\title{
Exploring Thermal Comfort Band for Healthcare Workers in Remote Clinics in Hot and Arid Climates: An Approach for Building Performance Improvement
}

\author{
Samuel Urom Udom, \\ University of Canberra, Canberra, Australia \\ Faculty of Arts and Design, Department of Architecture \\ Samuel.udom@canberra.edu.au
}

\begin{abstract}
The direct relationship between maintaining comfortable indoor environments and energy consumption means that understanding comfort requirements can positively impact costs associated with the planning, design, construction, operation and maintenance of healthcare clinics in remote communities. At present, performance of healthcare clinics with respect to Indoor Environmental Quality (IEQ) is unknown and there is still uncertainty regarding the perceptions of users on specific IEQ factors in this region. The objectives of this study are to determine the thermal performance of such clinics and how the occupants perceive their thermal environment. Operative temperature and relative humidity were monitored over 12 months in a clinic located in Wanarn community, Western Australia using data loggers. Subjective perceptions of the thermal environment were collected from 9 clinic staff through questionnaires at the same time. The results provide quantitative perspectives on the thermal requirements for clinics in remote settings, useful as inputs for building simulations. This has practical implications for improved building performance and energy efficiency that enhances satisfaction and wellbeing of the occupants.
\end{abstract}

Keywords: Thermal comfort, IEQ, Remote Australia, PMV, AMV, Healthcare Clinics, Energy Efficiency.

\section{Introduction}

The need to maintain thermally comfortable indoor environments in buildings has become synonymous with energy consumption (Andamon 2006). Thermal comfort standards such as ASHRAE 55, ISO 7730 and CEN15251 are notable standards for determining acceptable indoor conditions for occupants in a building based on Fanger's predicted mean vote (PMV) model in mechanically ventilated buildings. The model was developed based on temperate climates in Europe using university students as subjects in a controlled environment (Fanger 1970). These standards provide the platform for benchmarking acceptable comfortable indoor thermal conditions that aid the setting of temperature benchmarks for energy efficient designs through building simulations. However, many researchers (De Dear, Leow et al. 1991, de Dear and Fountain 1994, Karyono 1995, Kwok 1997, Cena and De Dear 1998, Hwang, Lin et al. 2007, Nasrollahi, Knight et al. 2008, Shaharon and Jalaludin 2012) have since applied this model in different geographical locations and building types to test its applicability in the prevailing climates in order to address environmental and human sustainability concerns. The findings from such studies have shown that the comfort range varies in various situations, implying that thermal comfort is contextual but internationally recognised thermal comfort standards are not. What is comfortable changes with time, place and season. It may also denote a social dimension that is dependent on culture and climate for instance, opportunities to modify parameters like clothing and activity level will enable individuals to be more comfortable (Cole, Robinson et al. 2013). Remote communities in Australia present unique characteristics in terms of their climatic, geographical, social, cultural and political realities when compared to city counterparts. This means that thermal comfort requirements will vary hence the need to establish thermal comfort parameters specific to remote communities based upon which sustainable design decisions can be proposed/made. This will provide baseline data for architects, designers and other built environment stakeholders to test alternative design scenarios for improved building performance via simulations to harness the environmental, economic and health benefits of high performing buildings, in this case healthcare clinics in the region. This in turn will help improve health outcomes in the region.

Abbreviations: ASHRAE, (American Society of Heating, Refrigerating and Air-Conditioning Engineers), PMV, (Predicted Mean Vote), CEN, (European Committee for Standardization), IEQ, (Indoor Environmental Quality), OT, (Operative Temperature), Clo, (Clothing Insulation). Met, (Metabolic rate), CRANA, (Council of Remote Area Nurses of Australia), RAN, (Remote Area Nurse), ATSIC, (Aboriginal and Torres-Strait Islander Commission), TCS, (Thermal Comfort Survey), CBE, (Centre for Built Environment). PPD, (Percentage of Persons Dissatisfied), TSS, (Thermal Sensation Scale), AMV, (Actual Mean Vote). 


\section{Background}

Healthcare is provided in complex and energy-intensive facilities that range from critical care hospitals to medical office buildings. In general, they account for a remarkable fraction of the energy consumption in the utility buildings sector, due in large part to the very high energy intensity levels of hospitals and other inpatient care facilities(Buonomano, Calise et al. 2014). They have the highest energy consumption per unit floor area in the buildings sector (Gaglia, Balaras et al. 2007). The continuous use of heating and cooling equipment to maintain satisfactory thermal environments for the occupants plus the use of artificial lighting on a continuous basis in several electrical health equipment, result in a relatively higher energy consumption when compared to other building types (Santamouris, Dascalaki et al. 1994, Alexis and Liakos 2013). They are designed for the long term use with an average lifetime usually over 50 years, during which the building will be retrofitted and renovated more than once (Technologies 1997). While healthcare facilities possess these special characteristics that lead to the higher energy consumption, the high energy use can be significantly reduced with net economic benefit to the health sector (Singer 2010) as evident in countries like Germany and the Netherlands whose potential energy savings have been estimated at $20 \%$ and 44\% respectively (Technologies 1997). In remote Australia, health services are very different to their city counterparts. The facilities are generally smaller but play a vital role in the provision of community-wide integrated health services (Committee 2012). Remote Australia has notably different demographic and socioeconomic characteristics when compared to the rest of Australia (Maru, Chewings et al. 2012). These characteristics usually create some unique challenges for health services delivery resulting in residents of remote Australia recording poorer health outcomes and exhibiting higher health need than their city counterparts (Wakerman, Humphreys et al. 2008). Healthcare delivery in the region comes at a significantly higher cost (Zhao, Hanssens et al. 2006) and this cost increases with the degree of remoteness (Committee 2012). The need to improve health outcomes for residents of remote Australia means that more facilities will be required to increase access to healthcare and shorten the distance of travel to access healthcare services in the region. This will mean more operational costs for existing clinics as well as more upfront costs for providing new clinics. This puts financial strain on those responsible for providing healthcare access to remote communities such as the Department of Health and state governments. Despite the challenges, remote communities present a unique opportunity to develop a methodology for quantifying and improving building performance of its health facilities. That is, reflective of smaller type healthcare facilities while capturing the characteristic differences applicable to its locality. Therefore, this study aims to identify and benchmark acceptable comfort conditions for the healthcare workers so that energy requirements to maintain these conditions can be adequately assessed via simulations. These measures will maximize efficiencies, reducing operational cost and offer valuable insights as to how clinics operate in remote communities.

\section{Remote Context of the Study}

Remote communities in Australia are characterised by the diversity based on degree of remoteness, culture, low population density that is also ageing, limited infrastructure, harsh climatic conditions and higher costs associated with healthcare delivery (Health 2013). These facilities provide community-wide integrated health services that include mental health services, oral health, community and aged care, in addition to social services. These communities also face the challenge of attracting and retaining medical workforce leading to a situation where fewer locally available specialists are required to provide services to a more dispersed population (Ageing 2012). There is an uneven distribution of healthcare professionals across the country for example, in 2006, very remote areas had 58 generalist medical practitioners per 100000 population (compared to 196 per 100000 in capital cities ), 589 registered nurses per 100000 population (compared to 978 per 100000 in major cities) and 64 allied health workers per 100000 population (compared to 354 per 100000 in major cities) (Ageing 2012). According to the Council of Remote Area Nurses of Australia, CRANA data, there are 248 clinics staffed by 595 nurses in remote and very remote areas. There are 51 clinics with no resident remote area nurse, 72 that are single nurse posts and a further 61 in very remote areas staffed by only two remote area nurses, all providing 24 hour cover seven days a week. In the Northern Territory (NT) there are 78 very remote clinics dispersed across the state staffed by remote area nurses with very few having resident doctors. In actual fact, only nine of these towns and communities in the NT have resident doctors, the remainder receive intermittent visits dependant on medical availability (Wyber-Hughes 2004). It is therefore no surprise that residents of rural and remote communities experience poorer health outcomes and exhibit higher health need. This proportion increases with increasing remoteness, with Indigenous health outcomes lagging well behind those of other Australians (Humphreys and Wakerman 2008). The problems associated with health care delivery in remote Australia has been firmly established and there is considerable catch up to be achieved. This relates to the provision of more needed infrastructures, funding and service development. It is aimed at improving access to acceptable, adequately resourced, sustainable models of healthcare in rural and particularly remote areas, where health outcomes are worse and there is a high proportion of Indigenous residents. It is important to note that these problems do not only serve as obstacles to adequate health care provision in remote communities but also provide opportunities for innovation. 
Methodology

The research was established from three main stages: Case study characterization; thermal perception of the occupants; and an evaluation of thermal performance via calculations.

Case Study

Wanarn Community healthcare clinic is in the community of Wanarn located in the Ngaanyatiarraku Shire Council area in the Warburton Ward of the Aboriginal and TorresStrait Islander Commission (ATSIC) Western Desert Regional Council. It lies on the eastern side of Western Australia about $15 \mathrm{kms}$ from the Great Central Highway approximately $160 \mathrm{kms}$ north east of Warburton (Ngaanyatjarraku 2012). Wanarn community includes a population of about 180 people with most of the population demographic comprising older people and a few children. Community facilities at Wanarn include community store, ambulance service/emergency evacuation, mechanical workshop/fuel depot, Aged care persons centre, recreational facilities such as football oval, basketball court and a playground for small children, a health clinic and primary school (Western Australian Planning Commission 2004). The climate is classified as arid to semi-arid (Desert), with hot summers; temperatures are often above $40^{\circ} \mathrm{C}$ with moderately cool winters and often very cold nights. The meteorological view of the Aboriginal and Torres Strait Islander people is one of great diversity that can't be meaningfully simplified to a rigid European seasonal calendar for the entire continent. Because of all this, seasonal cycles as described by the various Aboriginal cultures differ substantially according to location. In western Australia, six seasons exists: Kambarang, Birak Bunuru (Dry and hot season - October to March) and Djeran, Makuru, Djilba (cool and wet season - April to September). Rainfall is erratic and difficult to predict (Meteorology 2016). To the north of the Lands, rain is distributed in a tropical and summer pattern. This study is discussed in the context of warm and cool seasons as per aboriginal climatic classifications. The clinic was built early 2015 and consist of a dialysis room, nursing station, emergency room, waiting room and office space. The building is characterised by steel framed metal cladded walls on the exterior with plasterboard and vinyl lining on the internal walls. Roof and walls are insulated, windows are single glazed, and cooling is achieved by mechanical means through split systems with no heating provided (Figure 1). The work force is typical to those found in remote communities comprising a Remote Area Nurse (RAN), a clinic manager, occupational therapist, chronic disease coordinator and cleaner as well as visiting professionals such as general practitioner (GP), allied health professional, and other specialist, thus a small sample size. The staff office highlighted in Figure 1 was selected for monitoring environmental conditions as this is the space actively occupied by clinic staff. The results presented here are based on the findings from monitoring environmental parameters of the office space and subjective perceptions of thermal conditions of the clinic staff in relation to the office space.
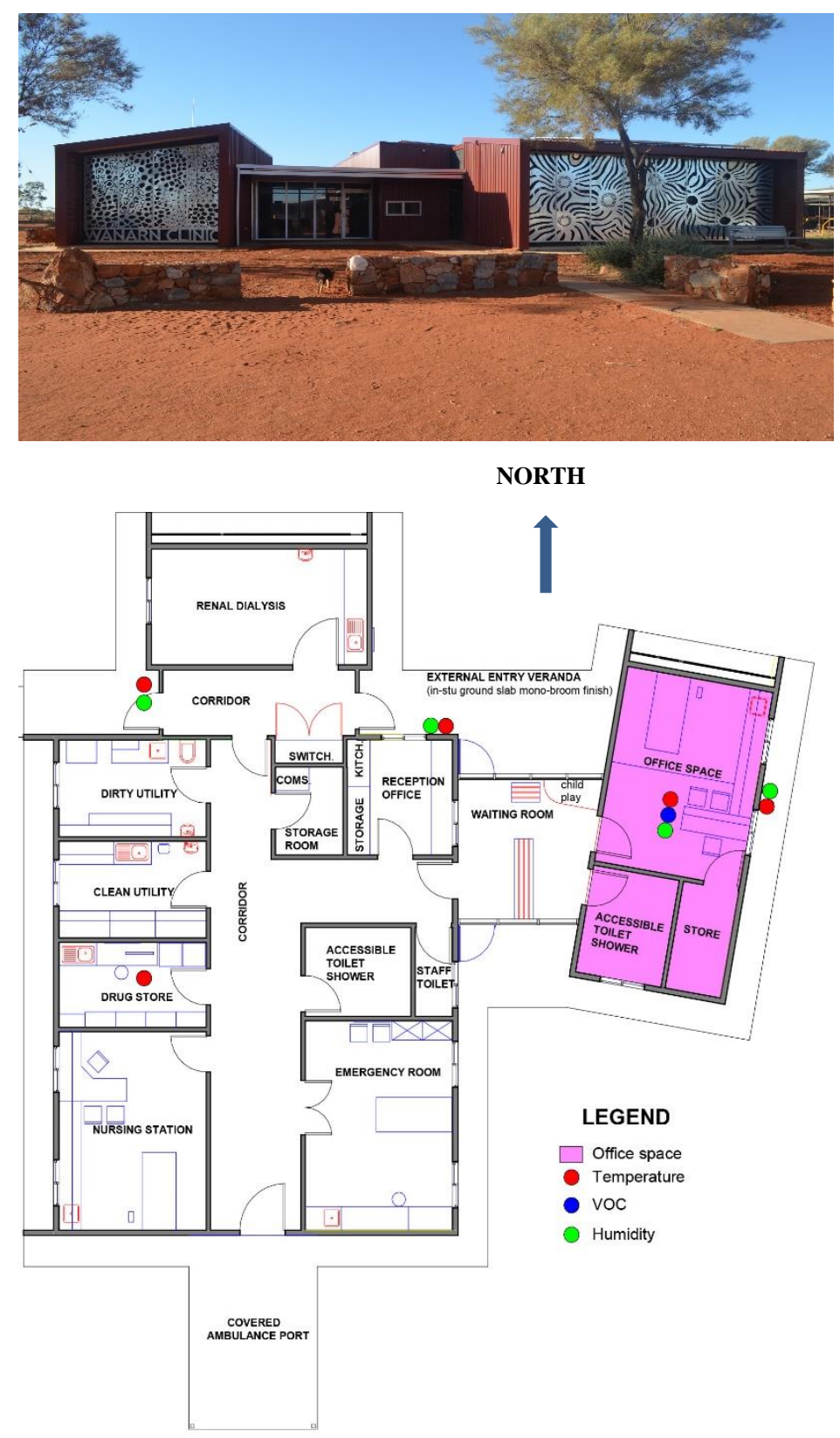

Figure 1: Floor plan and image of Wanarn healthcare clinic. Source: Author

\section{Thermal perceptions of occupants}

Several factors affect people's perception on their indoor environment and are generally classified in two categories: thermal environmental factors and personal factors (Tartarini, Cooper et al. 2017) A longitudinal investigation was carried out in August (Djilba) and October (Kambarang) in 2017 during which thermal comfort surveys (TCS), were administered to occupants of the building to gather responses relating to thermal sensation, temperature preference and thermal acceptability, clothing insulation level and metabolic 
activity. For air velocity, a steady state assumption of $0.2 \mathrm{~m} / \mathrm{s}$ was adopted in line with American Society for Heating, Refrigeration and Air-conditioning Engineers (ASHRAE) 55-2013 standard for AC buildings (ASHRAE 2013). The surveys were based on the application of three scales; Ashrae 7-point scale, McIntyre and acceptability scale. The surveys were administered to a total of 9 respondents ( 3 in Kambarang - summer and 6 in Djilba - winter) during operational hours $(8 \mathrm{am}-6 \mathrm{pm})$ from Monday to Friday in the clinic over 3 days. The respondents differed across both seasons. Table 1 gives a summary of the responses. The dates were identified from outdoor climatic data obtained from the closest weather station (Giles weather station) about $92 \mathrm{~km}$ from Wanarn. The survey also covered aspects of work area satisfaction, general thermal comfort, ventilation, lighting, noise, indoor air quality, personal control, productivity and health. Data on metabolic rates and clothing insulation were based on the provisions of ASHRAE 55 standard for values of clothing and activity types and applied in thermal comfort calculations using the Center for Built Environment, CBE thermal comfort calculation tool. Table 2 presents a summary of clothing insulation (Clo) and metabolic rates (Met) from the survey. Clo and Met. values for winter months are 0.53 and 1.25 respectively while summer recorded Clo and Met. values of 0.5 and 1.1 respectively.

Table 1: Summary of thermal comfort response votes in summer and winter months showing percentage of satisfaction and dissatisfaction.

\begin{tabular}{|c|c|c|c|c|c|c|c|}
\hline \multirow{3}{*}{ ASHRAE 7-Point Scale } & -3 & -2 & -1 & 0 & 1 & 2 & 3 \\
\hline & & & & & & & \\
\hline & Cold & Cool & Slightly cool & Neutral & Slightly warm & Warm & Hot \\
\hline Acceptability & \multicolumn{2}{|c|}{ Unacceptable } & \multicolumn{3}{|c|}{ Acceptable } & \multicolumn{2}{|c|}{ Unacceptable } \\
\hline Mclyntre Preference Scale & \multicolumn{2}{|c|}{ Want warmer } & \multicolumn{3}{|c|}{ No change } & \multicolumn{2}{|c|}{ Want cooler } \\
\hline \multicolumn{8}{|l|}{ Summer Months } \\
\hline Respondent 1 & & & & & & \multicolumn{2}{|c|}{ - } \\
\hline Respondent 2 & \multirow{2}{*}{\multicolumn{2}{|c|}{ - }} & & \multirow{2}{*}{\multicolumn{2}{|c|}{ - }} & & \\
\hline Respondent 3 & & & & & & & \\
\hline \multicolumn{8}{|l|}{ Winter months } \\
\hline Respondent 4 & & & & - & & & \\
\hline Respondent 5 & & & & - & & & \\
\hline Respondent 6 & & & & • & & & \\
\hline Respondent 7 & & & & - & & & \\
\hline Respondent 8 & & & & - & & & \\
\hline Respondent 9 & & & & - & & & \\
\hline Total & \multicolumn{2}{|c|}{$11.50 \%$} & & $77 \%$ & & \multicolumn{2}{|c|}{$11.50 \%$} \\
\hline
\end{tabular}

Table 2: Metabolic rate and Clothing insulation values for respondents during hot and cold seasons

\begin{tabular}{|c|c|c|c|c|c|c|c|c|}
\hline & $\begin{array}{c}\text { Respon } \\
\text { dent }\end{array}$ & Gender & $\begin{array}{c}\text { Age } \\
\text { bracket }\end{array}$ & $\begin{array}{l}\text { Period lived in } \\
\text { community } \\
\text { (Months) }\end{array}$ & $\begin{array}{l}\text { Hours worked } \\
\text { per week }\end{array}$ & $\begin{array}{c}\text { Period worked } \\
\text { in the building } \\
\text { (Months) }\end{array}$ & $\begin{array}{c}\text { M } \\
\text { (Met) }\end{array}$ & $\begin{array}{c}\text { Icl } \\
\text { (Clo) }\end{array}$ \\
\hline Summer & 1 & M & $50+$ & 14 & $37-48$ & 14 & 1.1 & 0.34 \\
\hline \multirow{3}{*}{\begin{tabular}{|l} 
Season \\
Djilba
\end{tabular}} & & & & & & & & \\
\hline & 2 & F & $50+$ & 6 & $49+$ & $<12$ & 1.1 & 0.64 \\
\hline & 3 & $\mathrm{~F}$ & $21-29$ & 7 & $13-24$ & $<12$ & 1.1 & 0.53 \\
\hline \begin{tabular}{|l} 
Average \\
\end{tabular} & & & & & & & 1.1 & 0.5 \\
\hline Winter & 4 & F & $50+$ & No response & 12 & $<12$ & 1.1 & 0.18 \\
\hline Season & & & & & & & & \\
\hline \multirow[t]{5}{*}{ Kambarang } & 5 & F & $50+$ & 5 & $49+$ & $<12$ & 1.1 & 0.81 \\
\hline & 6 & F & $50+$ & 4 & $25-36$ & $<12$ & 1.1 & 0.7 \\
\hline & 7 & $\mathrm{~F}$ & $50+$ & 36 & $37-48$ & $<12$ & 1.1 & 0.61 \\
\hline & 8 & M & $50+$ & No response & No response & $<12$ & 1.1 & 0.27 \\
\hline & 9 & M & $50+$ & No response & $13-24$ & $<12$ & 2 & 0.61 \\
\hline Average & & & & & & & 1.25 & 0.53 \\
\hline
\end{tabular}

Monitoring of thermal environmental factors

The surveys were accompanied by Simultaneous measurement of the indoor and outdoor climatic parameters of the office space in the building occupied by the clinic staff as identified in Figure 1. Hourly readings were recorded for temperature and humidity for a period of 12 months using Ezeio data loggers from January 2017 - December 2017. For each parameter measured, a total of 8753 data points was recorded making it a combined total of 17,506 data points. To be prepared for analysis, the data was reviewed to eliminate rogue/ unusual data points to maintain the integrity of the data for analysis. For the indoor temperature, readings below $16^{\circ} \mathrm{C}$ were ignored together with the corresponding values for humidity. The said temperature of $16^{\circ} \mathrm{C}$ was arrived at by identifying the coldest month according to the weather station for 2017 which happened to be in July. Subsequently, the lowest outdoor temperature from the data logger was identified at $4.8^{\circ} \mathrm{C}$ on the north, $2.8^{\circ} \mathrm{C}$ on the western side and $1.0^{\circ} \mathrm{C}$ on the eastern side of the building and the corresponding monitored indoor temperature was $16.0^{\circ} \mathrm{C}$ on the 7 th of July 2017 at 6:00am. The number of data points $16^{\circ} \mathrm{C}$ and above for indoor measurements and the fact that the minimum set point for the air-conditioner is $16^{\circ} \mathrm{C}$ justify its adoption as the minimum indoor temperature to be used for subsequent analysis. For the outdoor measurements, the same logic was applied which led to the exclusion of temperature readings below $1{ }^{\circ} \mathrm{C}$ together with corresponding humidity measurements from the data for subsequent analysis. To this end, 95\% of the data was found to be useful for analysis. Ezeio compatible data loggers operating on a Wireless Sensor Network (WSN) were selected to perform this study. To monitor indoor climatic variables, QHT 24R sensor was used to measure internal temperature and humidity. Accuracy of this logger for temperature was $\pm 0.2^{\circ} \mathrm{C}$ with a measurement range of $-30^{\circ} \mathrm{C}$ to $+70^{\circ} \mathrm{C}$ and humidity was $\pm 3 \%$ with a measurement range of $0 \%$ to $100 \%$. These are in line with the provisions of Ashrae Standard 55 for temperature and humidity measuring instruments. The loggers were mounted at a height of $1.1 \mathrm{~m}$ above finished floor level as the zone to take measurements of temperature and humidity. This is considered an approximate height that an occupant would be seated in the spaces and most likely to be engaged by thermal variables. Outdoor temperature was monitored using HOTT $010 \mathrm{VCP}$ Temp/Humidity sensor. It has four switchable temperature ranges of $-35^{\circ} \mathrm{C}$ to $+35^{\circ} \mathrm{C},-35^{\circ} \mathrm{C}$ to $+75^{\circ} \mathrm{C}, 0$ to $50^{\circ} \mathrm{C}$ and 0 to $+80^{\circ} \mathrm{C}$. The selected temperature range for this data logger to monitor the outdoor temperature was $-35^{\circ} \mathrm{C}$ to $+75^{\circ} \mathrm{C}$ and measurement accuracy of $+/-0.8$ Kelvin $\left(-275^{\circ} \mathrm{C}\right)$ at $+20^{\circ} \mathrm{C}$, based on place of installation and mounting position while the relative humidity has a measuring range of 0 to $100 \%$ r.H., operation range of 0 to $95 \%$ r.H. and accuracy of $+/-3 \%$ (20 to $80 \%$ r.H.), at $+20^{\circ} \mathrm{C}$ otherwise $+/-5 \%$ (Products 2017) 


\section{Temperature}

For the office space, the minimum, maximum and mean indoor temperatures for summer are $23.25^{\circ} \mathrm{C}, 28.96^{\circ} \mathrm{C}$ and $25.85^{\circ} \mathrm{C}$ respectively and in winter, $22.21^{\circ} \mathrm{C}, 26.77^{\circ} \mathrm{C}$ and $24.67^{\circ} \mathrm{C}$ respectively. Minimum, maximum and mean temperatures for the whole year are $22.73^{\circ} \mathrm{C}, 27.86^{\circ} \mathrm{C}$ and $25.26^{\circ} \mathrm{C}$ respectively. Similar readings for outdoor temperatures record minimum, maximum and mean values for summer at $26.32^{\circ} \mathrm{C}, 42.92^{\circ} \mathrm{C}$ and $36.16^{\circ} \mathrm{C}$ respectively. Minimum, maximum and mean values for winter months are $17.55^{\circ} \mathrm{C}, 31.24^{\circ} \mathrm{C}$ and $24.93^{\circ} \mathrm{C}$ respectively. Similar readings for the year recorded a minimum value of $22.04^{\circ} \mathrm{C}$, maximum of $37.08^{\circ} \mathrm{C}$ and mean of $30.55^{\circ} \mathrm{C}$. Table 3 . This is an indication that the building requires more of cooling than heating.

Table 3: Yearly summary, indoor and outdoor temperature.

\begin{tabular}{|c|c|c|c|c|c|c|}
\hline \multirow{2}{*}{ Month } & \multicolumn{3}{|c|}{ Indoor Temperature ${ }^{\circ} \mathbf{C}$} & \multicolumn{3}{|c|}{ Outdoor Temperature ${ }^{\circ} \mathbf{C}$} \\
\cline { 2 - 7 } & Min & Max & Mean & Min & Max & Mean \\
\hline Jan & 23.20 & 30.20 & 25.26 & 28.66 & 42.83 & 36.54 \\
\hline Feb & 22.00 & 27.30 & 25.45 & 29.72 & 42.60 & 37.68 \\
\hline Mar & 24.23 & 29.10 & 26.10 & 27.41 & 47.42 & 37.04 \\
\hline Apr & 24.19 & 28.67 & 25.79 & 18.96 & 34.90 & 27.19 \\
\hline May & 23.20 & 26.90 & 25.27 & 20.47 & 28.64 & 25.59 \\
\hline Jun & 18.99 & 25.35 & 22.55 & 14.16 & 27.55 & 19.89 \\
\hline Jul & 20.13 & 26.55 & 23.83 & 16.30 & 27.97 & 22.16 \\
\hline Aug & 23.61 & 26.55 & 25.17 & 14.18 & 31.20 & 24.60 \\
\hline Sep & 23.14 & 26.64 & 25.41 & 22.46 & 37.21 & 30.19 \\
\hline Oct & 23.15 & 28.23 & 25.59 & 20.10 & 40.82 & 33.47 \\
\hline Nov & 22.30 & 29.02 & 25.85 & 21.61 & 41.04 & 35.55 \\
\hline Dec & 24.67 & 29.92 & 26.86 & 30.46 & 42.82 & 36.72 \\
\hline & & & & & & \\
\hline Summer & 23.25 & 28.96 & 25.85 & 26.32 & 42.92 & 36.16 \\
\hline & & & & & & \\
\hline Winter & 22.21 & 26.77 & 24.67 & 17.55 & 31.24 & 24.93 \\
\hline & & & & & & \\
\hline All year & 22.73 & 27.86 & 25.26 & 22.04 & 37.08 & 30.55 \\
\hline
\end{tabular}

\section{Humidity}

For the office space, the minimum, maximum and mean humidity levels for summer are $15.55 \%, 65.62 \%$ and $41.12 \%$ respectively and in winter, $11.55 \%, 78.56 \%$ and $32.70 \%$ respectively. Minimum, maximum and mean temperatures for the whole year are $11.53 \%, 78.56 \%$ and $36.85 \%$ respectively. Similar readings for outdoor humidity record minimum, maximum and mean values for summer at $6.40 \%, 78.47 \%$ and $27.13 \%$ respectively. Minimum, maximum and mean values for winter months are $8.45 \%, 88.10 \%$ and $25.97 \%$ respectively. Similar readings for the year recorded a minimum value of $6.40 \%$, $88.10 \%$ and $26.55 \%$ respectively, according to Table 4 . This is an indication that the humidity in the summer months is better than during winter.
Table 4: Yearly summary, indoor and outdoor humidity

\begin{tabular}{|l|c|c|c|c|c|c|}
\hline \multirow{2}{*}{ Month } & \multicolumn{3}{|c|}{ Indoor Humidity \% } & \multicolumn{3}{c|}{ Outdoor Humidity \% } \\
\cline { 2 - 7 } & Min. & Max. & Mean & Min. & Max. & Mean \\
\hline Jan & 35.36 & 62.01 & 48.29 & 13.05 & 78.47 & 44.70 \\
\hline Feb & 27.99 & 65.00 & 41.70 & 9.51 & 49.56 & 27.29 \\
\hline Mar & 23.14 & 49.36 & 37.87 & 9.55 & 47.19 & 21.69 \\
\hline Apr & 14.27 & 78.56 & 38.47 & 10.89 & 88.10 & 33.22 \\
\hline May & 24.25 & 48.13 & 34.06 & 18.01 & 40.85 & 27.97 \\
\hline Jun & 11.53 & 62.49 & 33.50 & 10.51 & 81.99 & 30.19 \\
\hline Jul & 20.78 & 62.82 & 35.58 & 14.29 & 62.11 & 28.11 \\
\hline Aug & 20.17 & 38.39 & 29.08 & 13.52 & 44.24 & 21.19 \\
\hline Sep & 13.15 & 65.61 & 25.97 & 8.45 & 53.72 & 15.57 \\
\hline Oct & 22.72 & 65.52 & 41.00 & 9.62 & 59.07 & 24.44 \\
\hline Nov & 15.55 & 65.45 & 41.86 & 6.40 & 60.11 & 24.66 \\
\hline Dec & 19.25 & 48.05 & 36.89 & 10.80 & 48.98 & 22.46 \\
\hline & & & & & & \\
\hline Summer & 15.55 & 65.52 & 41.12 & 6.40 & 78.47 & 27.13 \\
\hline Winter & 11.53 & 78.56 & 32.70 & 8.45 & 88.10 & 25.97 \\
\hline All year & 11.53 & 78.56 & 36.85 & 6.40 & 88.10 & 26.55 \\
\hline
\end{tabular}

The Comfort Zone, PMV and AMV calculation using CBE Thermal comfort tool.

ASHRAE Standard 55 - 2013 defines the comfort zone as the thermal environment where the combinations of temperature, humidity, values of air speed, metabolic rate and clothing insulation is predicted to be acceptable. It is that temperature and neutral point $(0)$ on the thermal sensation scale where the PMV is between -0.5 and +0.5 . The Actual Mean Vote (AMV) is a derivation based on the resultant votes on the TSS and covers a wider margin in the region of -1 and +1 where $77 \%$ of the respondent voted. The AMV index therefore creates the link between subjective and objective data collection in the study for determination of acceptable comfort temperature. Within the range of PMV, the percentage of persons dissatisfied (PPD) is said to be less than or equal to $10 \%$ based on recommended values of metabolic rates between 1.0 and 1.3 met. In addition, clothing insulation of 1.0 Clo in winter and 0.5 Clo in summer and $80 \%$ acceptability of temperature within the environment in question is required (ASHRAE 2013). The European standard CEN15251 agrees with this while the International Standard Organisation ISO 7730 specifies three different categories of acceptable thermal environment; A, B and C. Category A represents the highest satisfaction of the environment where the PMV sits between -0.2 and +0.2 and PPD of less than or equal 6\%. Category B indicates the moderate satisfaction of the thermal environment where PMV values must be between -0.5 and +0.5, PPD less than or equal to $10 \%$. Eventually, category $\mathrm{C}$ denotes the minimum requirement with a PMV range between 0.7 and +0.7 and a PPD less than or equal to $15 \%$ (Standard 2005, Khan and Pao 2015). For steady state conditions, it is possible to determine PMV based on air temperature/ operative temperature (OT), humidity, clothing insulation and metabolic rate. This view is supported by several authors when calculating PMV for steady state conditions such as AC buildings which is a 
characteristic of the selected case study. Han et. al. (2014) highlighted the complexity and limitations of measuring all six variables and proposed a simplified predicted mean vote index. This view is further supported by Humphreys et.al. (2007) where they posit that air temperature and radiant temperature are not very different but in fact closer in practice in indoor environments based on thermal modelling of an empty room. It, therefore, can be used as an adequate measure of the thermal component of the thermal environment. Considering this, the variables measured for the calculation of PMV and AMV and determining acceptable thermal conditions include temperature, and humidity (from instrumentation), Clo. and Met. values from field survey of the respondents during winter and summer periods respectively.

The CBE thermal comfort calculation tool is one developed by Schiavon et.al. (2014) at the Centre for Built Environment $(\mathrm{CBE})$ at the University of California, Berkeley. This web-based tool provides a cross- platform that allows for thermal comfort calculations, visualisations, design and compliance according to ASHRAE Standard 55-2017 to be achieved by designers and practitioners. The CBE tool is web based, free, cross platform, does not need to be downloaded, works on any computer and allows the user to modify/ customise the values of inputs. Several values of temperature and humidity measured from instrumentation can be plotted on the charts, visualised with resultant calculations indicating compliance with ASHRAE Standard 55 - 2017 in an instant. PMV and PPD are determined thereby identifying comfort temperatures for analysis and decision making. The CBE tool was used to determine PMV for neutrality ( 0 on the TSS) and preferred $(-1,0+1$ on the TSS $=$ AMV) for every hourly reading of indoor temperature and humidity for the office space. Temperature and humidity inputs from instrumentation together with Clo. and Met. values for winter and summer would automatically calculate resultant temperatures and confirm compliance/non-compliance with ASHRAE 55 standard. As compliant combinations represent neutrality (0) on the thermal sensation scale, non-compliant combinations are also specific as to their position on the scale whether towards neutrality or away from neutrality and to what degree $(-1,-2,-3,0$ or $+1,+2,+3)$ (Table 5). Based on this, resultant temperatures within the respective regions of the thermal sensation scale was also recorded to enable determination of mean acceptable temperature based on AMV $(-1,0+1)$.
Table 5: PMV determination for neutral and preferred temperature using CBE thermal comfort calculation tool for a typical month: January 2017 from Monday to Friday (8am 6pm).

\begin{tabular}{|c|c|c|c|c|c|c|c|c|c|c|}
\hline Day & Month & Date & $\begin{array}{c}\text { Mean } \\
\text { Indoor } \\
\text { Office- } \\
\text { Temp. } \\
\left({ }^{\circ} \mathrm{C}\right) \\
\end{array}$ & $\begin{array}{l}\text { Mean } \\
\text { Indoor } \\
\text { Office - } \\
\text { RH }(\%)\end{array}$ & PMV & PPD \% & $\operatorname{SET}\left({ }^{\circ} \mathrm{C}\right)$ & $\begin{array}{l}\text { Thermal } \\
\text { sensation }\end{array}$ & Sensation & $\begin{array}{c}\text { ASHRA } \\
\text { E } \\
\text { Complia } \\
\text { nce } \\
\end{array}$ \\
\hline Monday & January & 2/01/2017 & 23.70 & 43.93 & -0.60 & 13.00 & 23.10 & -1.00 & Slightly Cool & No \\
\hline Tuesday & January & $3 / 01 / 2017$ & 23.20 & 46.26 & -0.75 & 17.00 & 22.60 & -1.00 & Slightly Cool & No \\
\hline Wednesd & January & $4 / 01 / 2017$ & 23.60 & 43.30 & -0.64 & 14.00 & 23.00 & -1.00 & Slightly Cool & No \\
\hline Thursday & January & $5 / 01 / 2017$ & 24.89 & 43.09 & -0.22 & 6.00 & 24.30 & 0.00 & Neutral & Yes \\
\hline Friday & January & 6/01/2017 & 25.64 & 44.40 & 0.04 & 5.00 & 25.10 & 0.00 & Neutral & Yes \\
\hline Thursday & January & $12 / 01 / 2017$ & 23.84 & 54.77 & -0.48 & 10.00 & 23.40 & 0.00 & Neutral & Yes \\
\hline Friday & January & $13 / 01 / 2017$ & 23.40 & 57.33 & -0.61 & 13.00 & 23.00 & -1.00 & Slightly Cool & No \\
\hline Monday & January & $16 / 01 / 2017$ & 23.48 & 53.52 & -0.61 & 13.00 & 23.00 & -1.00 & Slightly Cool & No \\
\hline Tuesday & January & $17 / 01 / 2017$ & 25.68 & 45.31 & 0.06 & 5.00 & 25.20 & 0.00 & Neutral & Yes \\
\hline Wednesd & January & $18 / 01 / 2017$ & 24.53 & 46.35 & -0.31 & & 24.00 & 0.00 & Neutral & Yes \\
\hline Thursday & January & 19/01/2017 & 23.81 & 62.01 & -0.44 & . & 23.50 & 0.00 & Neutral & Yes \\
\hline Friday & January & $20 / 01 / 2017$ & 28.88 & 48.47 & 1.15 & 33.00 & 28.70 & 1.00 & Slightly Warm & No \\
\hline Monday & January & $23 / 01 / 2017$ & 28.28 & 35.36 & 0.83 & 19.00 & 27.40 & 1.00 & Slightly Warm & No \\
\hline Thursday & January & $26 / 01 / 2017$ & 25.73 & 51.53 & 0.12 & 5.00 & 25.40 & 0.00 & Neutral & \\
\hline Friday & January & $27 / 01 / 2017$ & 26.85 & 45.88 & 0.45 & 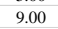 & 26.40 & 0.00 & Neutral & Yes \\
\hline Monday & January & $30 / 01 / 2017$ & 25.83 & 40.68 & 0.07 & 5.00 & 25.20 & 0.00 & Neutral & Yes \\
\hline Tuesday & January & $31 / 01 / 2017$ & 25.71 & 51.21 & 0.11 & 5.00 & 25.40 & 0.00 & Neutral & Yes \\
\hline
\end{tabular}

Results

\section{Thermal response vote:}

The distribution of thermal sensation votes and acceptability within the range of -3 (cold) to +3 (hot) based on the combined use of the Ashrae 7-point scale, Mclyntre scale and acceptability scale where the respondents voted is presented in Table 1 . All respondents voted within the range of -2 (cool) and +2 (warm) on the TSS. In summer, $33 \%$ of respondents found their thermal environment acceptable $(-1,0,+1$ on the TSS) while $67 \%$ desired change ( -2 and +2 on the TSS respectively). In winter however, $100 \%$ acceptability with the thermal environment $(-1,0,+1$ on the TSS) was reported with the respondents desiring no change, hence satisfied with the indoor environment. A similar result was recorded for humidity. This result shows that occupants can still be comfortable outside the neutral zone all year round. Among the 9 respondents/ clinic staff that participated in the study, only one of them (respondent 1) had spent up to 12 months working in the building and only respondent 7 had lived in the community for more than 12 months. The period spent in the community could have huge implications on the outcome on thermal comfort calculations since the ability to adapt to one's immediate environment over time impacts clothing insulation values. Ashrae 55-2013 recommends clothing insulation values for winter and summer as $1.0 \mathrm{Clo}$ and $0.5 \mathrm{Clo}$ respectively but in this case, the Clo values calculated from the survey administration results in $0.53 \mathrm{Clo}$ in winter and $0.50 \mathrm{Clo}$ in summer. The resultant preferred comfort temperature based on Fanger's PMV model is determined from thermal comfort calculations within the range of -1 and +1 on the TSS in line with the results from subjective votes from the questionnaires. It is on this basis that the AMV is established to benchmark acceptable indoor temperatures for building simulation and is considered the preferred temperature. 


\section{PMV(Neutral) and AMV (Preferred) temperatures}

Neutral temperature based on PMV calculations in the office space in summer is $25.71^{\circ} \mathrm{C}$ at $41.47 \%$ humidity. whereas, winter months is $25.39^{\circ} \mathrm{C}$ at $32.57 \%$ humidity. Neutral temperature over the 12-month monitoring period is $25.55^{\circ} \mathrm{C}$ at $36.93 \%$. Preferred temperature based on AMV calculations for the office space is $25.85^{\circ} \mathrm{C}$ at $41.00 \%$ humidity. Winter months is $24.82^{\circ} \mathrm{C}$ at $32.40 \%$ humidity and for the 12-month period, the preferred temperature for the office is $25.33^{\circ} \mathrm{C}$ at $36.69 \%$ humidity. Table 6 shows representations of PMV ( 0 on the TSS) and $\operatorname{AMV}(-1,0,+1$ on the TSS) temperatures respectively. AMV presents occupant comfort within a wider temperature range between $20^{\circ} \mathrm{C}$ and $30^{\circ} \mathrm{C}$ across both seasons with an AMV between -1.69 and +1.31 . when compared to $\mathrm{PMV}$ which entails a narrower range between $23.5^{\circ} \mathrm{C}$ and $27^{\circ} \mathrm{C}$ and PMV within the range of 0.48 and +0.50 , compliant with ASHRAE 55 standard. From 259 days of hourly readings with the exclusion of weekends, 193 days were compliant with ASHRAE standards based on the neutral sensation temperatures while AMV had 255 days. The difference between these two indices have huge implications for the sizing of airconditioning and subsequently energy consumption. This further implies that making design decisions based on PMV index where neutrality is considered optimum comfort temperature has the tendency for the over prediction of thermal comfort requirements. Consequently, the over specification of mechanical systems to maintain this condition thereby resulting in the higher energy demand and cost, and also, overcooling of the building to the detriment of the occupants within this geographic location and climatic zone.

Table 6: Acceptable temperatures based on PMV and AMV determination using CBE thermal comfort calculation tool for a typical year, summer and winter seasons respectively from 8 am to 6pm, Monday to Friday.

\begin{tabular}{|l|c|c|c|c|c|}
\hline & Summer & Winter & All Year & Temp. Range & PMV Range \\
\hline $\mathrm{PMV}^{\circ} \mathrm{C}$ & 25.71 & 25.39 & 25.55 & $23.50-27.00$ & $0.48-0.50$ \\
\hline $\mathrm{AMV}^{\circ} \mathrm{C}$ & 25.85 & 24.82 & 25.33 & $20.00-30.00$ & $-1.69-1.38$ \\
\hline
\end{tabular}

\section{Discussion / Conclusion}

The need to improve health outcomes for residents of remote communities in Australia mean that an increase in the access to healthcare facilities is needed in these regions. Achieving this comes at significantly higher cost when compared with urban counterparts due to the challenges associated with the remote context. Sustainable design solutions can help reduce costs associated with the design, construction and operation of healthcare clinics with an understanding on the thermal requirements of such buildings. This sort of information is currently lacking for remote communities hence the study investigated how a remote clinic performed with respect to the thermal performance, providing quantitative data based on the perception of the clinic workers. Results from thermal comfort field survey revealed that $77 \%$ of the staff were comfortable with their thermal environment and desired no change within the typical year. However, seasonal changes had a negative impact on the occupant thermal comfort in summer rather than winter. This means that more attention should be given to this season when proposing cost effective design solutions / strategies for improvement. The comparison between PMV and AMV temperatures reveals that people within this region may tolerate higher temperatures than those recommended by thermal comfort standards in hot and arid climates. This is also supported by previous studies in the works of (De Dear, Leow et al. 1991, de Dear and Fountain 1994, Karyono 1995, Kwok 1997, Cena and De Dear 1998, Hwang, Lin et al. 2007, Nasrollahi, Knight et al. 2008, Shaharon and Jalaludin 2012). Acceptable temperature of $25.33^{\circ} \mathrm{C}$ all year-round accounts for $98 \%$ of the readings and is considered suitable for use as a temperature setpoint for building simulation to test alternative design solutions. This is useful to provide guidance to building professionals and stakeholders on how clinics in remote areas should be designed, built and operated to enhance thermal comfort and maximize energy efficiency within the remote context. The resultant sample size for this study is typical for clinic staff in remote communities where a typical remote clinic would comprise of 1 Remote Area Nurse, 1 Occupational Therapist and 1 Clinic Manager. Other disciplines such as Chronic Disease Coordinator, Allied Health, General Practitioner, Cleaner and Visiting Specialists are usually spread across multiple remote clinics say a group of 5 clinics or more, hence the sample size is usually small for this category of cases. To address this limitation, further research is underway to extend this study to include subjective investigations on the thermal perceptions of the clinic users (Indigenous Australians). This will provide a stronger base for generalisation of findings and provide better insights on acceptable comfort temperatures useful for the exploration of design scenarios for clinics in remote communities via building simulations.

\section{Acknowledgements}

The author would like to acknowledge the Department of Health and Ageing, Canberra, Australia. The author express thanks to IBPSA and appreciate their valuable comments and feedback. 


\section{Reference}

AGEING, D. O. H. A. 2012. National Strategic Framework for Rural and Remote Health. In: AGEING, D. O. H. A. (ed.). Canberra, ACT.

ALEXIS, G. \& LIAKOS, P. 2013. A case study of a cogeneration system for a hospital in Greece. Economic and environmental impacts. Applied Thermal Engineering, 54, 488-496.

ANDAMON, M. Thermal comfort standards and building energy use in Philippine office environments. 40th Annual Conference of the Architectural Science Association ANZAScA, 2006. University of Adelaide, 66-72.

ASHRAE, A. S. 2013. Standard 55-2013. Thermal environmental conditions for human occupancy, 12

AUSTRALIA, C. O. R. A. N. O. \& (CRANA) Council of Remote Area Nurses of Australia (CRANA) Submission to the Productivity Commission.

BUONOMANO, A., CALISE, F., FERRUZZI, G. \& PALOMBO, A. 2014. Dynamic energy performance analysis: Case study for energy efficiency retrofits of hospital buildings. Energy, 78, 555-572.

CENA, K. \& DE DEAR, R. J. 1998. Field Study of Occupant Comfort and Office Thermal Environments in a Hot Arid Climate: Final Report-ASHRAE RP921, Institute of Environmental Science, Murdoch University.

COLE, R. J., ROBINSON, J., BROWN, Z. \& O'SHEA, M. 2013. Re-contextualizing the notion of comfort. Comfort in a Lower Carbon Society. Routledge.

COMMITTEE, R. H. S. 2012. National Strategic Framework for Rural and Remote Health. Barton: ACT.

DE DEAR, R. \& FOUNTAIN, M. 1994. Field experiments on occupant comfort and office thermal environments in a hot-humid climate.

DE DEAR, R., LEOW, K. \& FOO, S. 1991. Thermal comfort in the humid tropics: Field experiments in air conditioned and naturally ventilated buildings in Singapore. International Journal of Biometeorology, 34, 259-265.

FANGER, P. O. 1970. Thermal comfort. Analysis and applications in environmental engineering. Thermal comfort. Analysis and applications in environmental engineering.

GAGLIA, A. G., BALARAS, C. A., MIRASGEDIS, S., GEORGOPOULOU, E., SARAFIDIS, Y. \& LALAS, D. P. 2007. Empirical assessment of the Hellenic nonresidential building stock, energy consumption, emissions and potential energy savings. Energy Conversion and Management, 48, 1160-1175.
HAN, H., LEE, J., KIM, J., JANG, C. \& JEONG, H. 2014. Thermal comfort control based on a simplified Predicted Mean Vote index. Energy Procedia, 61, 970-974.

HEALTH, Q. D. O. 2013. Queensland rural and remote health service framework. In: BRANCH, P. A. P. \& DIVISION, S. P. A. P. (eds.). Queensland, Australia: State of Queensland Department of Health.

HUMPHREYS, J. \& WAKERMAN, J. 2008. Primary health care in rural and remote Australia: achieving equity of access and outcomes through national reform: a discussion paper.

HUMPHREYS, M. A., NICOL, J. F. \& RAJA, I. A. 2007. Field studies of indoor thermal comfort and the progress of the adaptive approach. Advances in building energy research, 1, 55-88.

HWANG, R.-L., LIN, T.-P., CHENG, M.-J. \& CHIEN, J.-H. 2007. Patient thermal comfort requirement for hospital environments in Taiwan. Building and environment, 42, 2980-2987.

KARYONO, T. H. 1995. Thermal comfort for the Indonesian workers in Jakarta: Adopting the current Ashrae standard for Jakarta would create cool discomfort and in addition waste energy - a greater understanding of true comfort range is called for. Building research and information, 23, 317-323.

KHAN, M. H. \& PAO, W. 2015. Thermal comfort analysis of PMV model prediction in air conditioned and naturally ventilated buildings. Energy Procedia, $75,1373-1379$.

KWOK, A. G. 1997. Thermal comfort in naturallyventilated and air-conditioned classrooms in the tropics. PhD Dissertation.

MARU, Y. T., CHEWINGS, V. \& SPARROW, A. 2012. Climate change adaptation, energy futures and carbon economies in remote Australia: a review of the current literature, research and policy. CRC-REP Working Paper CW005.(Ninti One Limited: Alice Springs, NT.).

NASROLLAHI, N., KNIGHT, I. \& JONES, P. 2008. Workplace satisfaction and thermal comfort in air conditioned office buildings: Findings from a summer survey and field experiments in Iran. Indoor and Built Environment, 17, 69-79.

NGAANYATJARRAKU, S. O. 2012. Wanarn [Online]. Available:http://www.ngaanyatjarraku.wa.gov.au/ind ex.php/our-region/community-information/wanarn [Accessed 8th September 2016].

SANTAMOURIS, M., DASCALAKI, E., BALARAS, C., ARGIRIOU, A. \& GAGLIA, A. 1994. Energy performance and energy conservation in health care buildings in Hellas. Energy conversion and management, 35, 293-305.

SCHIAVON, S., HOYT, T. \& PICCIOLI, A. Web application for thermal comfort visualization and 
calculation according to ASHRAE Standard 55. Building Simulation, 2014. Springer, 321-334.

SHAHARON, M. N. \& JALALUDIN, J. 2012. Thermal Comfort Assessment-A Study toward Workers' Satisfaction in a Low Energy Office Building. American Journal of Applied Sciences, 9, 1037.

SINGER, B. C. 2010. High Performance Healthcare Buildings: A Roadmap to Improved Energy Efficiency. Lawrence Berkeley National Laboratory.

STANDARD, I. 2005. 7730. Ergonomics of the thermal environment-Analytical determination and interpretation of thermal comfort using calculation of the PMV and PPD indices and local thermal comfort criteria. International Organization for Standardization: Geneva, Switzerland.

TARTARINI, F., COOPER, P. \& FLEMING, R. 2017. Thermal environment and thermal sensations of occupants of nursing homes: a field study. Procedia Engineering, 180, 373-382.

TECHNOLOGIES, C. F. T. A. A. D. O. D. E. 1997. Saving energy with Energy Efficiency in Hospitals.

TEMP, $\quad$ O. $2017 . \quad$ Available: http://www.onetemp.com.au/wireless-io-expanderfor-the-ezeio-controller [Accessed].

VCP. 2017. Air Quality (VOC) + Humidity $(r H)+$ Temperature (T) sensor QHT 24R [Online]. Available:

http://www.ventilationcontrolproducts.net/airquality-voc-sensor-qht-24r [Accessed].

WAKERMAN, J., HUMPHREYS, J. S., WELLS, R., KUIPERS, P., ENTWISTLE, P. \& JONES, J. 2008. Primary health care delivery models in rural and remote Australia-a systematic review. BMC Health Services Research, 8, 1.

WESTERN AUSTRALIAN PLANNING COMMISSION, W. 2004. Wanarn Layout Plan 1 Background Report [Online]. Available: www.planning.wa.gov.au/dop.../Wanarn_Layout_Pla n_1_Amendment_5_report.pdf [Accessed 9th September 2016].

ZHAO, Y., HANSSENS, P., BYRON, P. \& GUTHRIDGE, S. 2006. Cost estimates of primary health care activities for remote Aboriginal communities in the Northern Territory.

METEOROLOGY, B. O. (2016).

"The Six Seasons of WA." Retrieved 14/04/2019, from https://www.newintown.com.au/latest-newsblog/2015/6/19/the-six-seasons-of-wa 